\title{
A ENFERMAGEM EM SAÚDE MENTAL NO BRASIL: A NECESSIDADE DE PRODUÇÃO DE NOVOS CONHECIMENTOS
}

\author{
Sônia Barros* \\ Emiko Yoshikawa Egry
}

\begin{abstract}
RESUMO:A assistência psiquiátrica no Brasil após um século da sua institucionalização, em 1852, pouco se modificou, mantendo-se essencialmente restrita ao interior dos asilos e com uma função exclusivamente segregadora. Como resultado das exigências do dinamismo social, dos movimentos de transformação da assistência psiquiátrica na Europa e nos Estados Unidos e da mobilização dos profissionais da área de saúde mental, o Estado tem redefinido suas diretrizes políticas nas últimas décadas. Dessa forma, preconiza que a assistência seja feita de modo predominante extra-hospitalar, regionalizada e que o evento psiquiátrico seja atendido na própria comunidade. Os avanços do saber e da prática, em saúde mental, não foram acompanhados par e passo pela enfermagem que, desde o seu início até hoje, permaneceu essencialmente hospitalocêntrica, em que pesem as pressões e experiências no sentido de transformar sua prática e ensino, ao longo da história. As transformações necessárias só avançarão se os conhecimentos produzidos nesta área tomarem novos rumos uma vez que houve mudanças paradigmáticas na compreensão da saúde mental. Este estudo busca rastrear as grandes lacunas de conhecimento, que deverão ser preenchidas, para o realinhamento dinâmico da assistência de enfermagem em saúde mental. Algumas questões centrais que orientam a produção deste saber na realidade brasileira são discutidas.
\end{abstract}

UNITERMOS: Saúde Mental, Enfermagem em Saúde Mental, Assistência Psiquiátrica, Modelo Assistencial.

\footnotetext{
* Enfermeira. Mestre em Enfermagem. Assistente do Departamento de Enfermagem Materno-Infantil e Psiquiátrica da Escola de Enfermagem da USP, disciplina Enfermagem Psiquiätrica.

* Enfermeira. Mestre em Enfermagem. Doutor em Saúde Pública. Professor Doutor do Departamento de Enfermagem em Saúde Coletiva da Escola de Enfermagem da USP.
} 


\section{INTRODUÇÃO}

Em nosso país, o modelo assistencial vigente no campo da assistência psiquiátrica ainda está centrado no leito psiquiátrico, utilizado quase como único recurso. É consenso entre técnicos, prestadores de serviço, governo e opinião pública, que esta assistência, de uma forma geral, é de má qualidade.

A assistência psiquiátrica no Brasil, após um século da sua institucionalização, em 1852, pouco se modificou, mantendo-se restrita ao interior dos asilos e com uma função exclusivamente segregadora.

O NASCIMENTO DA PSIQUIATRIA E DA ENFERMAGEM PSIQUIÁTRICA NO BRASIL

A criação do hospicio Pedro II, em 1852, assinala o marco institucional do nascimento da psiquiatria e da enfermagem psiquiátrica no Brasil. $O$ doente mental, que pode desfrutar durante longo tempo de apreciável grau de tolerância social e de relativa liberdade, teve essa liberdade cerceada junto a outros individuos ou grupos de indivíduos que, por não conseguirem ou não poderem adaptar-se a uma nova ordem social, passaram a ser vistos como uma ameaça a esta mesma ordem (RESENDE, 1987).

Assim, a partir do final da século XVIII as Santas Casas passaram a incluir entre seus hóspedes os doidos, dando-lhes porém tratamento diferenciado dos demais doentes: amontoou-os em porões, sem assistência médica, reprimidos por espancamentos ou contensão em troncos. 
De acordo com MEDEIROS (1977) e RESENDE (1987), a partir de 1830 começaram a surgir os primeiros protestos contra a precariedade das Santas Casas, contra o tratamento desumano que era dado aos loucos e críticas à violência e brutalidade a que os doentes eram submetidos.

Além disso, argumentava-se pela necessidade de criação de um espaço onde se tratasse os loucos, agora doentes mentais, segundo as teorias e técnicas já em prática na Europa. Nasceu assim o hospício Pedro II, em 1852, no Rio de Janeiro, com a função de remover e excluir o "elemento perturbador".

À época a enfermagem era exercida pelas irmãs de caridade $e$ atendentes, sendo que suas ações caracterizavam-se pela repressão e punição. Persistiam as denúncias de maus tratos, superlotação, falta de assistência médica e a baixa qualificação e truculência dos atendentes.

Com a alteração da situação social e econômica que havia determinado o nascimento do hospicio, o emergente capitalismo pedia novas providências. processo político em curso, advindo da proclamação da República, resultou em novos confrontos de poder entre o Estado emergente, a classe médica, e a classe clerical. No interior do asilo tal disputa teve como consequência a saída das irmãs de caridade do Hospital Nacional dos Alienados, nova designação do Hospício Pedro II e, em 1890, foi criada a Escola Profissional de Enfermeiros daquele hospital que tinha por objetivo o preparo de pessoal para cuidar de doentes nos hospícios e hospitais civis e militares. Este periodo foi configurado como o marco divisório entre a psiquiatria empirica e a psiquiatria científica (GUSSI, 1987; REZENDE, 1987; SILVA FILHO, 1990). 
Assim, como afirma FERNANDES (1981), a primeira tentativa de sistematização do ensino da enfermagem brasileira foi na área psiquiátrica, onde o hospicio era o núcleo central da prática de enfermagem. $\grave{A}$ enfermagem foi outorgado o direito de controlar, disciplinar e reeducar o doente mental, estabelecendo e legitimando a vigilância e o confinamento como principais instrumentos da assistência.

Uma nova fase iniciou-se após a crise mundial de 1929 e, mais especificamente, com a segunda guerra mundial.

A avalanche dos problemas determinados pela crise da segunda década deste século levou o Estado brasileiro a tentar equacionar as questões sociais. Foram criadas as Caixas de Aposentadoria e Pensões pelos trabalhadores de setores especificos, que mais tarde foram incorporadas pelo Estado e reorganizadas em Institutos de Aposentadorias e Pensões, época em que a assistência médica enquanto um benefício foi mantida e ampliada.

Assim, a partir da década de 50 , a atenção psiquiátrica foi incorporada entre um dos benefícios no conjunto da assistência médica dos previdenciários.

Até o final da década de 50, o cuidado ao doente mental continuava essencialmente restrito ao interior dos asilos. A assistência psiquiátrica brasileira revelava, ainda, a extraordinária lentidão em tomar conhecimento das importantes transformações pelas quais passava a prática psiquiátrica na Europa e nos Estados Unidos após a Segunda Guerra Mundial.

De acordo com REZENDE(1987), o periodo que se seguiu ao movimento militar de 1964 foi $\circ$ marco divisório entre uma assistência 
eminentemente destinada ao doente mental "indigente" e uma nova fase a partir da qual se estendeu a cobertura ao conjunto dos trabalhadores e seus dependentes. O aumento da demanda e as precárias condições dos hospitais da rede pública fizeram com que o Estado optasse por contratar leitos em hospitais privados para atender os previdenciários. Com a rede ambulatorial incipiente, o quinquênio 65-70 foi marcado pelo fenômeno do afluxo maciço de doentes para os hospitais da rede privada (FERRAZ, 1983).

Manteve-se assim a prática da enfermagem psiquiátrica restrita aos asilos.

\section{AS ATUAIS MUDANÇAS NA SAÚDE MENTAL E OS REFLEXOS NA ASSISTÊNCIA DE EMFERMAGEM.}

A partir da década de 70 intensificaram-se as denúncias do que passou a ser conhecido como "indústria da loucura". As críticas mais contundentes eram relativas ao dispêndio de enormes recursos financeiros e a característica "cronificadora" da assistência.

O sistema acolhia as denúncias de seus criticos, tanto que emergiu uma infinidade de propostas e ordens de serviços, oriundos do Ministério da Saúde, de Secretarias Estaduais e do Instituto Nacional de Previdência Social (INPS). Todas elas tinham em comum a diretriz de manter o doente na comunidade e não afastálo do seu vínculo com o trabalho (BRASIL, 1983).

Deve-se ressaltar que era um periodo de grande aquecimento da economia e de escassez de mão de obra. Além disso, os movimentos de 
transformação da assistência psiquiátrica, iniciados após a Segunda Guerra Mundial, na Europa e nos Estados Unidos passaram a ter grande influência nos programas de saúde mental da América Latina e do Brasil.

Dentre os principais movimentos reformistas, de maior relevância, PITTA-HOISEL(1984) cita as comunidades terapêuticas e a anti-psiquiatria na Inglaterra, o "setor" da política da França, o movimento de saúde mental comunitária nos Estados Unidos e a psiquiatria democrática italiana.

Seguindo este movimento, diversos países da América Latina, incluindo o Brasil, definiram em documentos conjuntos os principios básicos para nortear os rumos da psiquiatria em seus paises, em direção às ações preventivas (OMS, 1975; OPS, 1983; ALARCON, 1986).

Em novembro de 1990 a OPAS/OMS convocou e realizou uma Conferência Regional em Caracas, para a reestruturação da atenção psiquiátrica na América.

O documento final desta Conferência, denominado "Declaração de Caracas", reconhece que: a atenção psiquiátrica convencional não permite alcançar os objetivos compatíveis com uma atenção comunitária descentralizada, participativa, integral, contínua e preventiva. $\mathrm{E}$ ainda, que a reestruturação da atenção psiquiátrica na região implica a revisão crítica do papel hegemônico e centralizador do hospital psiquiátrico na prestação de serviços. O Brasil, participante desta Conferência, foi signatário desta Declaração (OPAS/OMS, 1992).

Na década de 80, o Estado Brasileiro, duplamente pressionado pela recessão econômica e pela insatisfação da sociedade frente à má qualidade dos 
seus serviços assistenciais, procurou redefinir diretrizes para a área de saúde. PITTA-HOISEL(1984) assinalou que nesse momento houve uma convergência de principios revelados em vários documentos oficiais. Tais documentos explicitam diretrizes que deverão nortear a assistência psiquiátrica e, entre elas, o de regionalizar e integrar os recursos de saúde, públicos e privados, com ênfase nos cuidados primários.

VASCONCELOS (1992) afirma que a principal origem do modelo de serviços hierarquizados em saúde mental reporta-se às formulações da psiquiatria preventiva norte americana dos anos 60 , cuja primeira sistematização foi feita por Caplan. E ainda, que o modelo de integração de serviços de saúde mental à rede de saúde, dentro da proposta do Sistema Único de Saúde, vem sendo historicamente expresso em sucessivos planos federais (PISAN, CONASP, AIS, SUDS e SUS), estaduais e municipais desde os fins dos anos 70.

Diante destas transformações o hospital/asilo, tal como se apresentava, não mais atendia às demandas sociais: a psiquiatria vai procurando modificar suas características medievais e incorporar conceitos tais como os da comunidade terapêutica, psiquiatria social, psiquiatria preventiva e psiquiatria comunitária. Com estes marcos de referência, organiza-se uma rede de serviços assistenciais não hospitalares sem que houvesse porém a real transformação do saber e da prática psiquiátrica tradicional.

Segundo FERNANDES (1981), ocorreu então uma mudança básica da estratégia de intervenção das práticas psiquiátricas: a intervenção no corpo individual confinado passa para a penetração no conjunto do espaço social, submetendo a sociedade a um crescente processo de psiquiatrização. Agora, passa a ser objeto de ação da psiquiatria os "distúrbios e os conflitos" decorrentes 
das relações que as pessoas mantêm no trabalho, na escola, na familia, e não somente os "doentes mentais". Sob este prisma, a psiquiatrização da sociedade ganha espaço em nome de uma pretensa ação preventivista.

O processo de psiquiatrização configura-se, não somente pela ampliação do objeto de intervenção mas também pela extensão de serviços de saúde mental, incorporando grandes parcelas da população através da política de expansão da rede ambulatorial.

Neste contexto, as ações de enfermagem, que até então vinham sendo centradas na estratégia de segregação e confinamento, tornam-se incompativeis com essas mudanças. Ao redefinir e reorganizar o modelo de assistência, abre-se para a enfermagem um campo mais abrangente e com raio de ação mais ampliado. $\mathrm{Se}$, antes limitava-se aos cuidados dos doentes hospitalizados, passa ela agora a ocupar-se também dos conflitos e das inadaptações, ou seja, a incorporar a atenção aos sadios. Seu objeto torna-se mais complexo e amplo, pois trata-se agora da saúde mental (FERNANDES, 1987).

É importante ressaltarmos que a enfermagem brasileira, neste contexto, foi fortemente influenciada pela psiquiatria preventiva e comunitária, como pode-se perceber através de diversos textos escritos por enfermeiros, que relatam experiências e propostas de assistência baseados em Caplan (FERNANDES e TEIXEIRA, 1979; LUIS, 1985; RODRIGUES, 1986).

Frente a este quadro algumas considerações fazem-se necessárias:

- Apesar de incorporar o discurso comunitário com ênfase na extensão de cobertura, nos programas preventivos e ambulatoriais, a prática de 
enfermagem ainda busca âncora no modelo hospitalar de prestação de serviços:

- A participação da enfermagem no processo de ambulatorização é escassa;

- Nas escolas de enfermagem, observa-se uma predominância de explicações biológicas e psicológicas sobre a causalidade das doenças mentais, bem como sobre os cuidados correlatos à instalação de terapêuticas medicamentosas;

- A enfermagem, ao mistificar o social coloca obstáculos para a apreensão das questões da saúde e da saúde mental dentro da concepção da determinação social do processo saúde-doença, impossibilitando a projeção das ações de intervenção que ultrapasse os limites da concepção biologizante e psicologizante;

. Esta situação tem conduzido a assistência de enfermagem psiquiátrica para ações cada vez mais distantes das necessidades de saúde da maioria da população.

É necessário enfatizar que, como afirma ALVES et al (1992), no Brasil dos anos 80 ocorre um aprofundamento da crise do modelo assistencial hospitalocêntrico. Essa crise decorre em boa medida da falência ideológica dos princípios de sustentação daquele modelo.

Além disso, a análise desse período também demonstra que não basta propor uma nova racionalidade na assistência em saúde mental, sem colocar em xeque a essência da psiquiatria enquanto saber e prática de intervenção. $O$ 
exercicio manicomial pode continuar presente nas práticas do ambulatório, da psiquiatria preventiva ou comunitária, no local de trabalho ou na família, em que pese a mudança na organização do sistema.

A reforma psiquiátrica, ora em andamento, engloba princípios como a democratização dos serviços, universalização e equidade, tal como na reforma sanitária em geral, mas necessariamente deve incluir o desenho de um novo modelo de serviços, que tenha a cidadania do usuário do serviço de saúde, como enquanto premissa fundamental. Isto implica em uma necessária ruptura com o paradigma manicomial (DELGADO, 1992).

Como afirmam PITTA e BEZZERA (1992), nesta busca de novos paradigmas para uma nova prática encontra-se o dilema transformação/substituição do hospital psiquiátrico, onde se identificam duas posições: uma delas advoga a permanência do espaço hospitalar especializado para o tratamento psiquiátrico - o hospital psiquiátrico - desde que assuma o compromisso de modernização e humanização; a segunda, baseada em experiências alternativas não-hospitalares, pretende substituir o manicômio por uma rede de serviços sócio-sanitários diversificados em termos de modelos teórico-práticos, mas regidos pelo mesmo modelo teórico-filosófico.

O PROJETO de Lei 3657 (1989) de Paulo Delgado é um instrumento jurídico-político que assegurará, uma vez aprovado, a disseminação e o fortalecimento dessas experiências de transformação paradigmática da assistência psiquiátrica. 
Este Projeto de Lei, que surge no âmbito da reforma psiquiátrica brasileira, impôs urgência ao debate sobre a natureza das mudanças que a psiquiatria estava a exigir no país.

Consoante a "Declaração de Caracas", o Projeto de Lei traz em seu primeiro artigo a proibição em todo território nacional da expansão da rede de leitos financiados pelo Estado. Em seguida, indica os instrumentos de planificação necessários para a instalação e funcionamento de recursos não manicomiais de atendimento, tais como psiquiatria em hospital geral, hospital dia, centro de atenção, centro de convivência e outros.

O novo paradigma, que se constituirá num novo modelo assistencial, necessita superar modelos hegemônicos no campo da saúde mental e da psiquiatria, a partir do questionamento das instituições que a própria psiquiatria produziu, assim como do questionamento dos seus conhecimentos, poderes e códigos de comportamento.

Concordamos com ROTELLI (1991) ao afirmar que o novo campo terapêutico aberto pela desinstitucionalização é um locus no qual deve constituir-se um novo saber, agregando outros saberes além daqueles a que tradicionalmente se recorre, para que dêem conta de articular as necessidades sócio-individuais dos usuários dos serviços com a dinâmica de reprodução social de classe.

É fundamental investir na formação dos profissionais de saúde mental, orientada para a "desconstrução" das várias formas de opressão, exclusão e anulação dos doentes mentais. 
Nesse contexto, a enfermagem brasileira necessita buscar mais intensamente a crítica e a reflexão da prática e do ensino de enfermagem na área de saúde mental.

\section{CONSIDERAÇÕES FINAIS OS RUMOS DA INVESTIGAÇÃO CIENTÍFICA EM ENFERMAGEM FRENTE A MUDANÇA PARADIGMÁTICA}

Frente às mudanças paradigmáticas na compreensão da saúde mental, torna-se fundamental construir conhecimentos que levem às transformações necessárias do conjunto de saberes da enfermagem.

Para isto é necessário que os pesquisadores no campo da enfermagem em saúde mental repensem algumas questões centrais que orientam a constituição deste saber, ou seja, que contemple:

- a superação do conjunto de aparatos científicos, legislativos e administrativos, de códigos de referência cultural e de relações de poderes, estruturados em torno de um objeto bem delimitado: a doença;

. a ruptura do paradigma clínico com caráter reducionista, recortado no âmbito exclusivamente biológico dos fenômenos relativos ao processo saúde-doença mental;

- a ruptura da relação mecânica causa-efeito na análise da constituição da loucura; 
. a explicitação dos marcos conceituais que embasam as novas práticas não manicomiais e, ao mesmo tempo, do próprio processo de trabalho da enfermagem em saúde mental para o reordenamento da finalidade, do meio e do objeto, enquanto elementos constitutivos deste processo;

- a reflexão e a revisão dos processo de qualificação do profissional de modo a instrumentalizar os enfermeiros para a intervenção no campo da saúde mental, reconhecendo-a necessária dentro de processos de trabalho multi-agente e multi-profissional, e em diferentes niveis de atenção à saúde;

. a construção da relação agente-usuário fundada na compreensão do processo saúde-doença socialmente determinado, superando o recorte da "doença".

. a construção de projetos de intervenção assistencial de enfermagem ancorados na necessidade dos pacientes enquanto indivíduo-social.

Finalizando, frente ao predomínio e hegemonia das pesquisas da enfermagem dentro da visão funcionalista, que respondem ao paradigma anterior, é necessária a mudança paradigmática do marco teórico-metodológico da investigação, que possibilite a aproximação dos objetos fenomênicos através de referenciais teórico-metodológicos que dêem conta da sua totalidade dinâmica $e$ histórica.

A adoção destes referenciais possibilitará o desenvolvimento das pesquisas que re-orientarão a teoria e a prática da enfermagem na saúde mental 
para a re-definição da sua praxis alicerçada na compreensão da articulação do nexo bio-psíquico como totalidade do corpo social.

\section{REFERÊNCIAS BIBLIOGRÁFICAS}

1. ALARCÓN, R.D. La salud mental en América Latina: 1970-1980. Bol. Ofic. Sanit. Panam., 101:67-92, 1986.

2. ALVES, D.S.N.; SEIDL, E.M.F.; SCHECHTMAN, A.; CORREIA e SILVA, R. Elementos para uma análise da assistência em saúde mental no Brasil. In: CONFERENCIA NACIONAL DE SAÚDE MENTAL, 2, Brasília, 1992. A reestruturação da atenção em saúde mental no Brasil. Brasília, Ministério da Saúde, Coordenação de Saúde Mental, 1992. p.46-59.

3. BRASIL. Ministério da Previdência e Assistência Social. Instituto Nacional de Assistência Médica da Previdência Social. Programa de reorientação da assistência psiquiátrica. Brasília, 1983.

4. DELGADO, P.G.G. Reforma psiquiátrica e cidadania: o debate legislativo. Saúde em Deb., (35):92-84, 1992.

5. FERNANDES, D.A.B. \& TEIXEIRA, E.M.R. Enfermagem em saúde mental comunitária. Enf. Atual.1(4):2-4, 1979.

6. FERNANDES, J.D. A enfermagem no contexto da saúde mental. Rev. Baiana Enf., 1 ( $\mathrm{n}^{\circ}$ especial):7-23, 1981,

7. FERNANDES, J.D. A formação do enfermeiro psiquiátrico no contexto social e político brasileiro. Rev. Baiana Enf., $\underline{3}(1 / 2): 30-52,1987$.

8. FERRAZ, M.P. de T. Prioridades em saúde mental. Arq. Coord. Saúde Ment. Est. São Paulo, 44:9-20

9. GUSSI, M.A. Institucionalização da psiquiatria e do ensino de enfermagem no Brasil. Ribeirão Preto, 1987, [Dissertação. de Mestrado - Escola de Ribeirão Preto da USP] 
10. LUIS, M.A.V. Assistência de enfermagem à gestante com ênfase em sua saúde mental. Rev. Paul. Enf., $\underline{5}:(2): 8-91,1985$.

11. MEDEIROS, T.A. Formação do modelo assistencial psiquiátrico no Brasil. Rio de Janeiro, 1977. [Dissertação de Mestrado - Instituto de Psiquiatria da Universidade Federal do Rio de Janeiro].

12. ORGANIZACIÓN MUNDIAL DE LA SALUD. Organización de servicios de salud mental en los paises en desarrolo. Ginebra, 1975. (Série de Informes Técnicos, n. 564).

13. ORGANIZACIÓN PANAMERICANA DE LA SALUD. Dimensiones sociales de la salud mental. Washington, 1983. (Publicación Científica, $n^{\circ} 446$ ).

14. ORGANIZAÇÃO PANAMERICANA DA SAÚDE. Declaração de Caracas. In: CONFERÊNCIA NACIONAL DE SAÚDE MENTAL, 2, Brasilia. 1992. Brasília, Ministério da Saúde, Coordenação de Saúde Mental, 1992. p.3031.

15. PITTA-HOISEL, A.M. Sobre uma política de saúde mental. São Paulo, 1984. [Dissertação Mestrado - Faculdade de Medicina de USP]

16. PITTA, A.M.F. \& BEZERRA, J.B. Tecnologias, modelo assistencial e saúde mental no Brasil. [Apresentado na $9^{a}$ Conferência Nacional de Saúde, Brasilia, 1992].

17. PROJETO DE LEI 3.657, de 1989. Dispõe sobre a extensão progressiva dos manicômios e sua substituição por outros recursos assistenciais, e regulamenta a internação psiquiátrica compulsória.

18. RESENDE, H. Política de saúde mental no Brasil: uma visão histórica. In: BEZERRA JÚNIOR, B. Cidadania e loucura - Políticas de saúde mental no Brasil. Petrópolis, Vozez, 1987, Cap.1, p.1-73.

19. RODRIGUES, A.R.F. Enfermagem de saúde mental para mulheres em crise acidental. Ribeirão Preto, 1986. [Tese de Doutorado - Escola de Enfermagem de Ribeirão Preto da USP]

20. ROTELLI, F. A Lei 180 do reforma psiquiátrica: os problemas na sua aplicação, Divulg.Saúde Deb, (4):p.119-22, 1991. 
21. SILVA FILHO, J.F. O sistema de saúde e a assistência psiquiátrica no Brasil. J. Bras. Psiquiat. 39:135-46, 1990.

22. VASCONCELLOS, E.M. Contribuição à avaliação da estratégia de integração do programa de saúde mental no sistema único de saúde no Brasil recente. J.Bras.Psiquiat., 41:283-6, 1992. 